\title{
The development of environmental science agency for primary school students through an environmental entrepreneurship intervention programme
}

\author{
Antigoni Komodiki $^{1}$ (D) Alexandros Charalambides ${ }^{1}$ (D) Andri loannou ${ }^{2}$ (D)
}

Received: 9 August 2021 / Revised: 9 August 2021 / Accepted: 7 September 2021 /

Published online: 5 November 2021

(c) The Author(s) 2021

\begin{abstract}
The development of environmental science agency (ESA) is considered very important for the sustainability and conservation of the environment and the safeguarding of the cultural heritage. It is enhanced through experiential programmes and participatory actions that shape future environmental behaviour. ESA consists of three components: knowledge, role development and agency about the environment and the current issues affecting it. The present research was designed to explore how an environmental entrepreneurship intervention programme with primary school students can promote the development of their ESA. The study involved 34 primary students, aged 11-12, who participated in an environmental entrepreneurship educational programme. It follows a mixed methods design using quantitative and qualitative methods of data collection and analysis, namely pre- and post-students' questionnaires and teachers' interviews. The results indicate the development of knowledge and roles components, while the third component, agency, seems to diminish. The results of this study seem to be suggesting that late childhood is a good period to invest in the development of ESA, by offering environmental entrepreneurial programmes to students that might leverage their future intentions and willingness in taking action towards the sustainability of the environment and the cultural heritage. Future studies should continue to investigate the relationship between environmental entrepreneurship education and the development of ESA.
\end{abstract}

Keywords Entrepreneurship education · Environmental entrepreneurship · Environmental science agency · Primary education

Antigoni Komodiki

aa.komodiki@edu.cut.ac.cy

Extended author information available on the last page of the article 


\section{Introduction}

In 2006, the European Union Educational Policy issued the Framework for the Development of Lifelong Learning as its key direction for the future citizens of the Union. The particular policy identified eight key competencies which were described as essential for the success in lifelong learning of European citizens and for the improvement in employability skills (Official Journal of the European Union, 2006). From then onwards, educational authorities in the member states, educational organizations as well as other public and private stakeholders have been studying and researching these key competencies. Among these key competencies the notions of the sense of initiative and entrepreneurship were highlighted.

Entrepreneurship, although a term derived from economics, was adapted to the needs of education and it was applied at all levels, on a mandatory or optional basis. The definition of the term was hence enriched to a more inclusive concept. According to the European Commission (2013, p. 5) "Entrepreneurship education is more than preparation on how to run a business. It is about how to develop the entrepreneurial attitudes, skills and knowledge which, in short, should enable a student to "turn ideas into action"', Being entrepreneurial is more than a competence. It involves the creation of the entrepreneurial mindset that can be applied in all spheres of life, from 'nurturing personal development, to actively participating in society, to (re)entering the job market as an employee or as a self-employed person, and to starting up ventures (cultural, social or commercial)' (European Commission, 2016, p. 6).

Entrepreneurial programmes are mostly based on experiential learning theory and practice that take place within a social environment. To 'learn' entrepreneurship, you need to dive deep into the entrepreneurial experience (Williams Middleton et al., 2014). A research published by the Innovation Cluster for Entrepreneurship Education, a project managed by Junior Achievement Europe, the leading organization in the implementation of entrepreneurial programmes in Europe, reveals that transversal skills, soft skills and entrepreneurial intentions are developing through specific experiential entrepreneurial programmes (Johansen, 2018).

These initiatives were, however, followed by extensive criticism from researchers and pedagogists. Researchers question the legitimacy of entrepreneurship as a pedagogically established approach based on (1) the confusion on the basic assumptions underlying entrepreneurial teaching or teaching approaches (Hagg \& Peltonen, 2011; Jones \& Iredale, 2010), (2) the absence of the ontological, axiological and epistemological positions of entrepreneurship education (Jones, 2019) and (3) the misleading definitions, including purpose, value, orientation and nature of the discipline (Draycott \& Rae, 2011). Therefore, a void is identified not only on epistemology and pedagogy but also in the evaluation of entrepreneurship education. Researchers tend to evaluate either students' entrepreneurial skills (soft or transversal) (Galloway et al., 2005; Hassi, 2016; Oosterbeek et al., 2010) or their entrepreneurial intentions (the desire to own or start a business) (Bae et al., 2014).

One of the main challenges that humanity faces nowadays is the environmental crisis, both in natural and built environment. Commencing in the USA during the 
1980s, environmental movements began asking for protection and sustainability (Dunlap \& Scarce, 1991). The social, economic and cultural dimensions of the environmental crisis have been increasingly recognized and sustainable development became an even more prominent term. According to Zachariou et al. (2011) sustainable development requires the reassessment of one's way of living, in a way that ensures the continuing capacity of the planet for meeting the needs of both current and future generations.

In the framework of entrepreneurship, a new term is developed namely the environmental entrepreneurship. Environmental entrepreneurship is a multicomponent construct which can be also found in the literature as green, eco or sustainable entrepreneurship and is characterized by three aggregated theoretical dimensions: (a) duality of goals (financial and environmental), (b) environmental agency and (c) environmental value creation (Antolin-Lopez et al., 2019). Its implementation addresses environmental challenges, towards the efficient operation of the market and for the enhancement of ecological sustainability (Dean \& McMullen, 2007). For researchers, environmental entrepreneurship is a solution for addressing financial development in a sustainable way. Based on this assumption, students need to be transformed through education in order to be able to leverage future environmental challenges. In simple words, they should develop a sense of agency.

In order to deal with current environmental issues, raise awareness to students and develop their intentions to take future action regarding the environment, Ballard et al. (2017) raised the conceptual framework of ESA. ESA is the way that 'young people use environmental science learning and participation as a foundation for action related to environmental sustainability' (Ballard et al., 2017, p. 67). In this framework, learning is being examined as environmental science agency, by exploring the different ways that students use learning and participation as a basis to empower them to act for the environment. The scientific procedure empowers the youth in order to become participants and engage in environmental issues, so as they gain awareness and align with the values, goals and norms of the subject. The engagement to the above leverages youth to become agents of environmental change, namely the change to the environment.

Natural environment embraces the nature's creations while the built environment is defined as the part of the physical environment that is constructed by human activity (Saelens \& Handy, 2008). Both the natural and the built environment are considered vital for the future of a sustainable world (European Commission, 2019). In that framework, European Commission announced the European Year of Cultural Heritage 2018 aiming to celebrate cultural heritage as a common good and a shared resource that needs to be safeguarded, preserved, enhanced and promoted.

According to the Framework for Action on Cultural Heritage (European Commission, 2019, p. 11) 'Cultural Heritage is an irreplicable resource that can enhance social capital, boost economic growth and secure environmental sustainability'. Based on the urgent need to protect all forms of the unique cultural heritage before irreversible damage is done (Van Balen, 2014), it was decided to combine environmental entrepreneurial learning and teaching with cultural heritage as a vital pillar of the environment. 
The present research was designed to explore how an environmental entrepreneurship programme with primary school students can promote the development of their ESA. The aim is to explore the possibility of enhancing environmental agency through the experience of entrepreneurial learning by promoting and sustaining the cultural heritage.

The study is guided by the overarching research question: 'How, if at all, primary education students demonstrate environmental agency that is developed out of an environmental entrepreneurship programme?'. The specific research questions of the study are the following:

$R Q 1$ What is the impact of an environmental entrepreneurship intervention programme on students' perceived ESA? Are there differences in students' perceived knowledge, roles and agency from pre- to post-testing?

$R Q 2$ How does the programme promote ESA development from the teachers' perspective?

\section{Literature review}

\section{Environmental entrepreneurship education}

Environmental entrepreneurship has raised the engagement of scholars and practitioners, in the past few decades. It became an important global phenomenon in the 1980s based on its promise to address the complicated 'unsolved' environmental issues, creating innovations and opportunities for a different and a more sustainable management of the environment (Antolin-Lopez et al., 2019). Scholars refer to environmental entrepreneurship by using different terms to describe the phenomenon, such as green entrepreneurship, eco-entrepreneurship, eco-preneurship and sustainable entrepreneurship (Schaper, 2002). The European Commission adopts the definition of Schaper (2012) to define Green Entrepreneurship as 'the entrepreneurship that has a positive effect on environment and can be seen as a move to a more sustainable future' (Bacigalupo et al., 2016, p. 20). In all cases, innovation is considered to be one of the important building blocks of the environmental entrepreneurship framework, which is considered very critical to leverage social change (De Bruin and Lewis, 2015) and economic growth (European Commission, 2016). Policy documents (European Commission, 2016) and other studies (Gevrenova, 2015) have highlighted the role that innovation plays in addressing global challenges such as the environmental degradation and climate change. Thus, environmental entrepreneurship has the ultimate goal of introducing environmentally friendly innovations which are aligned with economic development.

Environmental entrepreneurship is currently being practiced in schools, mainly in secondary education, as an extra-curricular activity aiming to develop a green mindset for future generations of entrepreneurs (Greent, 2017), enhance sustainable innovation and at the same time ecological sustainability (Dean \& McMullen, 2007).

There are only a few examples of environmental entrepreneurship that are practiced in schools (Greent, 2017) or they are offered as an afternoon activity (Yeep, 
2017). The programmes are optional, and they are mostly experiential offering the students the opportunity to practice the development of businesses that offer environmentally friendly products. The engagement to environmental entrepreneurship activities seems to develop students' knowledge and minds on the concept of environmental entrepreneurship and foster their motivation for further development of their entrepreneurial competencies (Greent, 2017; Yeep, 2017). Overall, programmes lack of scientific evaluation and robust evidence on the impact and efficacy of environmental entrepreneurship education.

\section{Environmental science agency}

Human agency has been extensively studied by scholars in order to define how human beings act upon their lives and intentionally influence their functioning and life circumstances (Bandura, 2001). It has its foundation in self-efficacy, meaning the belief in one's personal efficacy to achieve goals and to have the power to effect changes (Bandura, 2006). Different theories have emerged to explain the agency that leverages positive environmental action and change.

In the framework of science, Basu et al. (2009) have proposed the critical science agency (CSA) framework. The CSA development involves lessons through which students develop deep understandings of science concepts, following by the ability to take action at the individual and community levels. It is based in three key components which are:

a. Understanding science content and the processes, skills and scientific modes of inquiry associated with the content. This includes the knowledge gained across projects, concepts, practices and epistemologies that students use, data collection and analysis, dissemination of analysis and investigation of complex systems.

b. Identifying areas of their own expertise. Students critically define their role in the procedure, as well as the role of others, they become specialists in specific areas, they take ownership and leadership in process and they begin to develop identity as people who work for positive change.

c. Using science expertise as a foundation for change. This includes student' shifts in position or identity that extend beyond the projects. They gain new perspectives on the importance of changes they can make to systems, and they see healthy ecosystems as a community asset. They form personal ambitions and goals and take actions to direct the world in sustainable paths, spotting opportunities outside of the programme.

Taking into consideration that the present study is dealing with the environment, we urged to search in depth the environmental science agency (ESA) as described by Ballard et al. (2017). ESA is based on CSA components and examines 'learning in terms of the ways that young people use science learning and participation as a foundation for action related to environmental sustainability' (Ballard et al., 2017, p.67). The framework is based on the active participation of students in existent environmental challenges, in order to motivate them to take action. Becoming a legitimate participant in a 
community that engages in environmental sciences requires that students not only gain proficiency with tools to research and act on these issues, but also that they align, at least in part, with the values, goals and norms of these communities (Lave \& Wenger, 1991). This approach to research can foster new knowledge, learning and action to leverage positive social and environmental change through reorienting the standard process of knowledge production (Ballard \& Belsky, 2010).

The environmental programmes, in order to draw on environmental science agency, should reframe the objectives, the content and the structure around activities that enhance children in acting with those tools of science in ways that are meaningful, substantial, and support the development of sustainable social and environmental systems (Ballard et al., 2017), thus becoming agents of change (Freire, 1974). According to Gough (1999) empirical constructive approaches tend to privilege particular forms of knowledge that are assumed to be instrumental in enabling humans to develop subjectivity, pursue 'rational' choices and move from environmental knowledge into active concern.

Since the field of the ESA is still young, a small number of studies were undertaken (see Barton \& Tan, 2010; Bigger \& Webb, 2010; Ballard et al., 2017). Although these studies contributed to the environmental science agency theorization, none of them shed light in the relationship between environmental entrepreneurship and ESA. This led us to the decision of designing and conducting the present study aiming to address 'How, if at all, primary students demonstrate environmental agency that is developed out of an environmental entrepreneurship programme?'.

\section{Methodology}

The study followed a mixed methods design using quantitative and qualitative methods of data collection and analysis, namely pre- and post-student's questionnaires and teachers' interviews. The specific research questions of the study are the following:

RQ1 What is the impact of an environmental entrepreneurship intervention programme on students' perceived ESA? Are there differences in students' perceived knowledge, roles and agency from pre- to post-testing?

$R Q 2$ How does the programme promote ESA development from the teachers' perspective?

The research design was approved by the Centre of Educational Research and Evaluation of Cyprus.

\section{The intervention programme}

The current intervention programme, namely the 'Environmental Entrepreneurship Guide', was designed by a team of school teachers who expressed interest to participate in the programme with the support of the researcher. The design is based on the British Council fully structured resource pack for teachers, namely 'Building Better 
Lives: Social Enterprise in schools' (British Council, 2016) that promotes the creation of innovative solutions (products or services) to address social needs.

The programme includes ten lesson plans ( $80 \mathrm{~min}$ each) that lead to the development of a student company with an environmental aspect that promotes sustainability in one or more ways. Taking cultural heritage as a factor of the environment, the Environmental Entrepreneurship Guide includes the exploration of the community's cultural heritage as a part of the environment, the awareness of the cultural heritage needs and challenges and the confrontation through the design and production of a sustainable solution, product or service. It concludes with the presentation pitching of the students' products in front of people.

The ten lessons were designed based on the ESA theory as set by Ballard et al. (2017), aiming to develop the three components, namely the knowledge, skills and norms, the roles and the environmental agency. To elaborate, when we aim in developing ESA, knowledge should be the primary target. For this to be realized, many activities were included to enhance knowledge about, in and for the environment and the cultural heritage (Tilbury, 1995). Knowledge, skills and norms are indirectly developed, during other activities such as the visit, the exploration of the challenges, the formation of the teams, the product suggestion and the pitching presentations. Roles are being developed when students identify their own areas of expertise within the programme, they take responsibly the role of communicating the new knowledge to others and they consider themselves as 'experts'. For this to be realized, activities were designed to enhance role development such as the community researcher, the journalist, the presenter and the role that students develop within their company (director, accountant, communications manager, production manager, designer, etc.) Environmental agency is identified as students' willingness to use the knowledge gained and the roles developed as a foundation for action and change related to environmental sustainability. Activities were designed to give the students the opportunity to reveal their leadership role during the project, to suggest sustainable solutions, to design sustainable products and services, to see cultural heritage as part of the community, to write and speak about their work in order to disseminate the results and use this specialization to lead other initiatives.

\section{Participants}

The headteacher, the teachers and the students of one urban primary school are the participants of the current study. The school is located just outside the city centre of Limassol, Cyprus, an area whose residents are of a middle socioeconomic background. A very limited percentage of students receive meals from the school (considered to be as of low socioeconomic background).

The study sample consisted of 34 students attending Grade 6 (11-12 years old). The demographic aspects of the students participated in the study are revealed in Table 1 . Out of 34 student-participants, $56 \%$ were boys and $44 \%$ were girls. A total of $26 \%$ of the students have an entrepreneur father and $18 \%$ reported an entrepreneur mother. The teachers had an extended experience in teaching 
ranging from 20 to 26 years. The headteacher of the school had an experience of 30 years in teaching and 10 years as a principal.

\section{Data collection}

\section{Students' perceptions survey}

To investigate RQ1, namely how the environmental entrepreneurship intervention programme was perceived by the participants a pre-post-questionnaire, was used aimed at addressing students' performance in ESA.

To test the results of the intervention programme to the ESA development, we modified the questions used for Ballard et al. (2017) research, adjusting them to the current context. We replaced the conservation of species and plants with that of the cultural heritage which, as a part of the environment, was our main way of examining the ESA growth. The questionnaire consists of 19 items, measured on a Likert scale (from $1=$ Strongly Disagree to $5=$ Strongly Agree). Based on validation procedures (Mavri et al., 2019) applied prior to the research, the questionnaire includes five subscales (factors) as follows: (a) environmental knowledge, (b) cultural heritage knowledge, (c) cultural heritage roles, (d) environmental agency and (e) cultural heritage agency, addressing the three components as stated and analysed by Ballard et al. (2017).

The subscales had acceptable internal consistency based on Cronbach's alpha reliabilities ranging from 0.653 to 0.940 in pre-test and from 0.820 to 0.916 in post-test (Table 2).

\section{Interviews}

The headteacher and the six teachers of the school participated in semi-structured individual interviews, at the completion of the intervention programme. An interview protocol was created to guide the questions and explore the teachers' perceptions with regard to the development of the ESA for students. The average time of the interviews was $30 \mathrm{~min}$.

Table 1 Demographic aspects of students

\begin{tabular}{lll}
\hline Demographic aspects & $N$ & Percentage (\%) \\
\hline Gender & 19 & 56 \\
Male & 15 & 44 \\
Female & & \\
Family background & 9 & 26 \\
Father entrepreneur & 6 & 18 \\
Mother entrepreneur & & \\
\hline
\end{tabular}




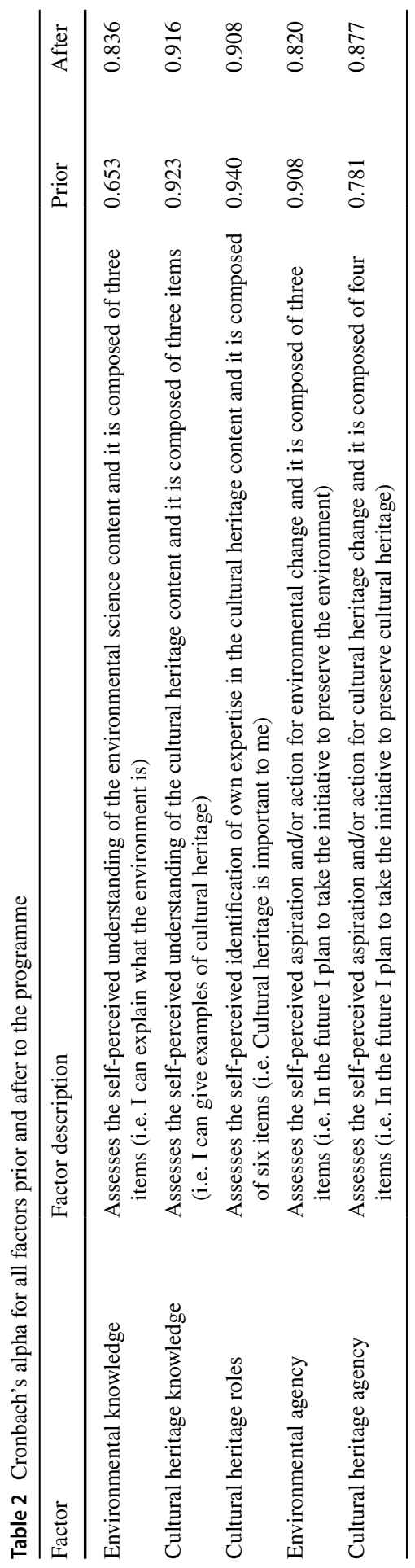


Table 3 Environmental science agency evaluation

\begin{tabular}{lllllllll}
\hline Factor & \multicolumn{2}{l}{ Pre-test } & & \multicolumn{2}{l}{ Post-test } & \multirow{2}{*}{ Sig } \\
\cline { 2 - 3 } & Mean & SD & & Mean & SD & \\
\hline Environmental knowledge & 3.84 & 0.82 & 3.83 & 1.00 & 0.943 \\
Cultural heritage knowledge & 2.45 & 1.34 & 3.23 & 1.15 & 0.000 \\
Cultural heritage roles & 3.23 & 1.27 & 3.54 & 1.01 & 0.084 \\
Environmental science agency & 3.92 & 1.24 & 3.47 & 1.07 & 0.001 \\
Cultural heritage agency & 3.05 & 0.86 & 2.83 & 1.05 & 0.117 \\
\hline
\end{tabular}

Thematic category Subcodes interviews and coding

\begin{tabular}{ll}
\hline Environmental science agency & Knowledge \\
& Roles \\
& Agency \\
\hline
\end{tabular}

\section{Analysis and results}

\section{The impact of the intervention programme on students' perceived ESA (RQ1)}

Paired-sample t-test analysis was conducted to examine whether the intervention programme yielded changes in the components of ESA, namely students' knowledge, roles and agency. The analysis indicated statistically significant gains in Knowledge and marginals (although not statistically significant) gains in Roles. More specifically, the knowledge about cultural heritage was statistically significantly increased after the intervention programme while the knowledge about the environment was the same in pre- and post-testing. Roles had a marginal increase from pre- to post-testing. The third ESA component, namely the Agency, seemed to diminish after the intervention programme. The results of the two tests are presented in the following paragraphs (Table 3).

\section{Teachers' perceptions on students' ESA development (RQ2)}

With regard to the teachers' perceptions, the data were coded in NVivo, following the thematic analysis suggested by Braun and Clarke (2012). The data set was systematically identified, organized and offered insights into patterns of meaning (themes). The data were coded under three subcodes, which directly linked to the teachers' perceptions of how students' knowledge, roles and agency had any significant change from pre to post programme intervention (Table 4).

\section{Knowledge}

The teachers were asked to state whether their students developed specific knowledge on the environment and the cultural heritage. All the teachers responded positively with reference to cultural heritage. 
'And they come much closer to culture, to the environment, they understand concepts and then they essentially try to offer, to adopt institutions, to deal with culture and to feel that it is their own responsibility. That it is something that belongs to them. Something they can contribute themselves. Both in the environment and in culture.' [Teacher 2]

They also expressed their satisfaction as they believe that the official curriculum does not promote cultural heritage as it should.

'First, they learn more about our cultural heritage. Because they also emphasized it, although it should be emphasized anyway in our curriculum, but because it was our goal, we paid more attention to it.' [Teacher 1]

Nevertheless, when they were asked about the knowledge developed in terms of the environment, the teachers stated that more dedicated activities focused on the environment are needed in order to enhance environmental knowledge.

In addition, teachers specified financial literacy, financial definitions and entrepreneurial terms as a new knowledge developed during the programme. Although financial literacy consists an objective of the health education lesson, the teachers who were interviewed stated that they do not have the time to teach those 'new things'.

'The concept of business, the concept of roles within a business, environmental business, cultural business. That's it. These are the concepts. That there is this side of the business, the examples, the environmental businesses you give them ... They didn't have this knowledge before. Like myself in the beginning of the programme.' [Teacher 1]

Skills development has been a key objective of the entrepreneurial programmes worldwide and a main concern of the scientific educational research on entrepreneurship (European Commission, 2013 - European Commission, 2016·Hassi, 2016). Parallel, skills development is crucial when students develop the capacity associated with content of the new knowledge. The teachers' interviews revealed significant development in specific students' skills, namely on creativity, collaboration, teamwork, critical thinking, responsibility, originality, communication, decision making, innovation, initiative and self-confidence. Also, the teachers pointed out the development of the entrepreneurial attitude and thinking to students, which under the appropriate circumstances could lead to the conservation and sustainability of both the environment and the cultural heritage.

Their minds become more entrepreneurial... [Teacher 7]

[They develop] creativity. They think of some ideas. And entrepreneur-

ship, which hides some creativity. Or an originality. They think this way. [Teacher 4]

I saw them being responsible. They wrote the text of the presentation by themselves. They didn't need anything. [Teacher 2]

Innovation! They create something new, from scratch. This is creativity and innovation. [Teacher 5] 


\section{Roles}

We aimed to explore teachers' views of the ways that students develop roles within their student company and more general within the programme and environmental science. Teachers pointed out that the students 'adopted' the programme and their student company and they took ownership of their learning process. They collaborated in order to create something that it was belonging to them. They felt that this collaboration could be of benefit to all.

'One piece of advice to each other, they splitted roles, got a job that seemed to work for the team. Those who made the product, who created it ... from the middle of the programme onwards, after finishing with the theories, it was all their own, it was all self-acting.' [Teacher 2]

The headteacher of the school had the opportunity to discuss with the students and follow their work during the whole programme. She stated that each time she was in the class for teaching another lesson, the students could not miss the chance to express their enthusiasm and talk about their role in the programme.

'They told me concepts they learned, they talked to me about their businesses, their names, their roles... [Teacher 7]

In order to develop their roles, students should leverage their own expertise to reflect and act on their lives and local communities (Ballard et al., 2017; Basu et al., 2009). For this to happen, students interviewed the people responsible for their place of visit, revealing significant interest to support them.

'They interviewed him (a special Cypriot artist), and they offered their own suggestions on how to better utilize or become more entrepreneurial, what else he could sell, or what else to do ... (for the Museum)' [Teacher 3]

The last lesson of the programme included a presentation pitch, during which students should convince the audience for the quality and value of their product. This seems to be a critical point of the intervention, as teachers identified. It helps students to establish their roles within their company and develop an expertise in order to transmit their knowledge and experience to the others.

[The presentation] 'It was very important. It reinforced them to decide on their final roles.' [Teacher 5]

'After the visit, the activities and examples began to become a little more tangible, and everything they learned theoretically started fleshing out. I think they started to understand. And that seemed to be their impatience to prepare the presentation.' [Teacher 1]

In order to develop a role within a specific field, it is very important to enhance the appreciation towards this field. Although not being specifically identified in the literature for the environmental science agency, it is vital to develop the appreciation of students towards the environment and the cultural heritage in order to legitimate agency furthermore. If we treat agency as a competence, we should take into 
consideration the MacArthur study, according to which competence is comprised of four elements: (1) understanding, (2) appreciation, (3) the ability to manipulate information rationally and (4) the ability to communicate a choice (Grisso \& Appelbaum, 1995). The study indicates appreciation as a main component to enhance competence, which in our case this may represent a step towards agency.

Teachers stated growth of the appreciation towards cultural heritage and the environment. They stated that the students behaved respectfully towards the cultural places they visited, something that was not happening before the programme. However, some teachers had their concerns when they were asked to answer regarding the appreciation for the environment.

...positive effect. We made them get involved, get interested, observe things that could go unnoticed, see buildings, see ... and want to improve it, protect it. [Teacher 1]

It had a great effect. Culture is also part of the environment. So, if something has an impact on the culture, it also has on the environment. [Teacher 4] ...their expressions, their answers, their discussions in the groups. I remember him saying, it doesn't matter if we don't get money, but they will get to know our culture. They wanted to give money to renovate the buildings that are left in time ... which are not preserved. It seemed that they had a concern, an interest that was starting to creep in ... That they were in the process of seeing things they didn't like and wanting to change, they noticed ... it looked like yes, I saw a change! [Teacher 2]

\section{Agency}

The teachers were asked to state whether they believe that their students have developed their environmental agency and give relevant examples.

Environmental agency was evident in many parts during the interviews. More specifically, teachers identified students' responses and answers during the lessons. They expressed their confidence that the knowledge and the roles that were developed during the lessons had an impact in enhancing the environmental agency.

One of the main findings is that in order to develop environmental agency, students should have programmes or lessons as part of their official curriculum. Their responses revealed also the impact of such programmes to the community and the environment.

'They themselves... and the environment .... and the society benefit from this programme...they can affect things to some extent. Make a small intervention.' [Teacher 4]

'That they can put in their little stone that they can make a difference in the future. For the society, the environment, the culture. I believe it gave them the opportunity to see something in the future, that they can do something...the programme taught them not to be disappointed. Not to be passive. To believe that nothing changes, that they can do nothing, just to mumble ... To see that the future is in their hands. They can create it the way they want it.' [Teacher 5] 


\section{Discussion}

Environmental entrepreneurship education is considered to be an innovation for schools around the world. Innovative change constitutes a dynamic process, during which innovative teaching and learning is being reflected, evaluated and reconsidered. The results may include improved learning practices and attitudes for students, new skills, attitudes or satisfaction for teachers or improved practical solutions for the school unit (Fullan, 2007).

The articles assesses the impact of environmental entrepreneurship education on the development of environmental science agency in primary school students. The intervention programme was implemented in the Cyprus context aiming to teach children aged 11-12 the basic entrepreneurial skills, through an experiential learning procedure. The process is based on the suggestion and the production of innovative solutions, products or services that promote the conservation and the sustainability of the environment and the cultural heritage.

The research questions were answered through qualitative and quantitative methods of data collection and analysis. First, the results of the quantitative research revealed significant gains in the first component of ESA, 'Knowledge'. Also, the growth in knowledge is presented as perceived by the teachers during the interviews. Overall, based on the findings we can conclude that the intervention programme leads to positive gains on students' knowledge about cultural heritage, considering the latter as part of the environment. The results confirm previous research on ESA development, where students used knowledge and skills in the research content settings to describe new knowledge specific to their research (Ballard et al., 2017).

The development of the second component of ESA, namely the 'Roles', also seems to grow marginally from pre- to post-testing. Yet, these gains are not statistically significant. According to the teachers, however, it is confirmed that students took on specific roles and recognized themselves as experts, both in running their business and in promoting the cultural heritage. This draws upon previous research that reveals that primary school is an appropriate level to invest in such change (Harris \& Ballard, 2021).

The third component of ESA, agency has diminished after the intervention programme. This can lead us to the conclusion that students might initially 'think' they are willing to act on the environment, giving a false self-perception, but when they experience what acting and changing entail, including commitment and workload, it seems that they are more reluctant to report that they are ready to work towards bringing change. However, the teachers' interview responses seem to indicate the development of environmental agency to students. Extended details and examples were given in order to emphasize the students' statements, experiences and behaviour during the programme. According to the teachers, significant positive gains were derived from the intervention programme, namely on the knowledge, the roles and the future intentions for action.

We should acknowledge that the sample of this study was small, which might have prevented us from detecting statistically significant differences. The study 
also focuses on the context of Cyprus. Nevertheless, these limitations do not undervalue the findings of importance of the work. The results should indeed be interpreted with caution while the study requires. The findings should still be useful to instructors and administrators who aim to promote environmental entrepreneurship education and should be transferable to similar context and settings.

\section{Conclusion}

The present research identified a link between the implementation of an intervention environmental entrepreneurship programme with primary school students and the development of their environmental science agency. The results of this study might be suggesting that late childhood (11-12 years old) is a good period to invest in developing environmental science agency that is a set of three components: the knowledge, the roles and the agency developed within the programme and meaning their future intentions and willingness for taking action towards the sustainability of the environment and the cultural heritage.

We believe that this study can further inspire research and practice in the field of environmental entrepreneurship education, and it can offer an insight of how environmental entrepreneurship can be important for a sustainable world.

Acknowledgements This project has received funding from the European Union's Horizon 2020 Research and Innovation Programme under Grant Agreement No 739578 and under Grant Agreement No 621584 and the Government of the Republic of Cyprus through the Deputy Ministry of Research, Innovation and Digital Policy.

\section{Declarations}

Conflict of interest The authors declare that they have no conflict of interest.

Open Access This article is licensed under a Creative Commons Attribution 4.0 International License, which permits use, sharing, adaptation, distribution and reproduction in any medium or format, as long as you give appropriate credit to the original author(s) and the source, provide a link to the Creative Commons licence, and indicate if changes were made. The images or other third party material in this article are included in the article's Creative Commons licence, unless indicated otherwise in a credit line to the material. If material is not included in the article's Creative Commons licence and your intended use is not permitted by statutory regulation or exceeds the permitted use, you will need to obtain permission directly from the copyright holder. To view a copy of this licence, visit http://creativecommons.org/licen ses/by/4.0/.

\section{References}

Antolin-Lopez, R., Martinez-del-Rio, J., \& Cespedes-Lorente, J. J. (2019). Environmental entrepreneurship as a multi-component and dynamic construct: Duality of goals, environmental agency, and environmental value creation. Business Ethics: A European Review, 28(4), 407-422.

Bacigalupo, M., Kampylis, P., Punie, Y., \& Van den Brande, G. (2016). EntreComp: The entrepreneurship competence framework. Publication Office of the European Union. 
Bae, T. J., Qian, S., Miao, C., \& Fiet, J. O. (2014). The relationship between entrepreneurship education and entrepreneurial intentions: A meta-analytic review. Entrepreneurship Theory and Practice, $38(2), 217-254$.

Ballard, H. L., \& Belsky, J. M. (2010). Participatory action research and environmental learning: Implications for resilient forests and communities'. Environmental Education Research, 16(5), 611-627.

Ballard, H. L., Dixon, C. G., \& Harris, E. M. (2017). Youth-focused citizen science: Examining the role of environmental science learning and agency for conservation. Biological Conservation, 208, $65-75$.

Bandura, A. (2001). Social cognitive theory: An agentic perspective. Annual Review of Psychology, 52(1), 1-26.

Bandura, A. (2006). Toward a psychology of human agency. Perspectives on Psychological Science, 1(2), 164-180.

Barton, A. C., \& Tan, E. (2010). We be burnin'! Agency, identity, and science learning. The Journal of the Learning Sciences, 19(2), 187-229.

Basu, S. J., Barton, A. C., Clairmont, N., \& Locke, D. (2009). Developing a framework for critical science agency through case study in a conceptual physics context. Cultural Studies of Science Education, 4(2), 345-371.

Bigger, S., \& Webb, J. (2010). Developing environmental agency and engagement through young people's fiction. Environmental Education Research, 16(3-4), 401-414.

Braun, V., \& Clarke, V. (2012). APA handbook of research methods in psychology: Vol. 2. Research designs, H. Cooper (Editor-in-Chief).

British Council (2016) Building better lives. Social Enterprise in schools: A resource pack for teachers. Retrieved September, 2017 from https:/www.britishcouncil.org/sites/default/files/social_enter prise_classroom_resource.pdf.

De Bruin, A., \& Lewis, K. V. (2015). Traversing the terrain of context in social entrepreneurship. Journal of Social Entrepreneurship, 6(2), 127-136.

Dean, T. J., \& McMullen, J. S. (2007). Toward a theory of sustainable entrepreneurship: Reducing environmental degradation through entrepreneurial action. Journal of Business Venturing, 22(1), 50-76.

Draycott, M., \& Rae, D. (2011). Enterprise education in schools and the role of competency frameworks. International Journal of Entrepreneurial Behavior \& Research., 17, 127-145.

Dunlap, R. E., \& Scarce, R. (1991). Poll trends: Environmental problems and protection. The Public Opinion Quarterly, 55(4), 651-672.

European Commission (2013) Entrepreneurship education: A guide for educators. Retrieved July, 2016 from http://ec.europa.eu/education/news/2013/20130923_en.htm.

European Commission (2016) Better regulations for innovation-driven investment at EU level. Retrieved January, 2020 from https://op.europa.eu/en/publication-detail/-/publication/404b82db-d08b-11e5a4b5-01aa75ed71a1/language-en.

European Commission (2019) European framework for action on cultural heritage. Retrieved December, 2019 from https://op.europa.eu/en/publication-detail/-/publication/5a9c3144-80f1-11e9-9f05-01aa7 5ed71a1.

Freire, P. (1974). The pedagogy of the Oppressed. Rappa Publications.

Fullan, M. (2007). The new meaning of educational change. Routledge.

Galloway, L., Anderson, M., Brown, W., \& Wilson, L. (2005). Enterprise skills for the economy. Education+ Training, 47(1), 7-17.

Gevrenova, T. (2015). Nature and characteristics of green entrepreneurship. Trakia Journal of Sciences, 13(2), 321-323.

Gough, N. (1999). Rethinking the subject: (De)Constructing human agency in environmental education research. Environmental Education Research, 5(1), 35-48.

Greent (2017) GREENT project: Final external evaluation report. Retrieved March, 2021 from http:// greentproject.eu/wp-content/uploads/2017/11/Final-External-Evaluation-Report.pdf.

Grisso, T., \& Appelbaum, P. S. (1995). The MacArthur treatment competence study. III. Law and Human Behavior, 19(2), 149-174.

Hagg, O., \& Peltonen, K. (2011). Towards a conceptual understanding of entrepreneurial pedagogy. In 8th ESU conference on entrepreneurship (2011) (pp. 1-27). Universidad de Sevilla.

Harris, E. M., \& Ballard, H. L. (2021). Examining student environmental science agency across school science contexts. Journal of Research in Science Teaching, 58, 906-934.

Hassi, A. (2016). Effectiveness of early entrepreneurship education at the primary school level: Evidence from a field research in Morocco. Citizenship, Social and Economics Education, 15(2), 83-103. 
Johansen, V. (2018). Innovation cluster for entrepreneurship education. Lillehammer, Norway, Østlandsforskning/Eastern Norway Research Institute. Retrieved April, 2021 from https://www.ostforsk.no/ wp-content/uploads/2018/01/201801_Innovation_Cluster_for_Entrepreneurship_Education_Revis ed_edition.pdf.

Jones, B., \& Iredale, N. (2010). Enterprise education as pedagogy. Education+ Training, 52(1), 7-19.

Jones, C. (2019). A signature pedagogy for entrepreneurship education. Journal of Small Business and Enterprise Development, 26(2), 243-254.

Lave, J., \& Wenger, E. (1991). Situated learning: Legitimate peripheral participation. Cambridge University Press.

Mavri, A., Ioannou, A., \& Loizides, F. (2019). On the Reliability and factorial validity of the assessment scale for creative collaboration. In IFIP conference on human-computer interaction (pp. 783-792). Springer, Cham.

Official Journal of the European Union (OJEU). (2006). Recommendation of the European Parliament and of the Council of 18 December 2006 on Key Competences for Lifelong Learning (2006/962/ EC). Retrieved October, 2017 from http://eur-lex.europa.eu/LexUriServ/LexUriServ.do?uri=OJ:L: 2006:394:0010:0018:en:PDF. http://icee-eu.eu/component/attachments.

Oosterbeek, H., Van Praag, M., \& Ijsselstein, A. (2010). The impact of entrepreneurship education on entrepreneurship skills and motivation. European Economic Review, 54(3), 442-454.

Saelens, B. E., \& Handy, S. L. (2008). Built environment correlates of walking: A review. Medicine and Science in Sports and Exercise, 40(7), 550-566.

Schaper, M. (2002). The essence of ecopreneurship. Green Management International, 38, $26-30$.

Schaper, M. (2012). Understanding the green entrepreneur. In M. Schaper (Ed.), Making ecoentrepreneurs: Developing sustainable entrepreneurship. Gower Publishing.

Tilbury, D. (1995). Environmental education for sustainability: Defining the new focus of environmental education in the 1990s. Environmental Education Research, 1(2), 195-212.

Van Balen, K. (2014). Creating the strategic research agenda. JPI Cultural Heritage and Global Change Strategic Research Agenda.

Williams Middleton, K., Mueller, S., Blenker, P., Neergaard, H., \& Tunstall, R. (2014). Experiencebased learning in entrepreneurship education-a comparative study of four programmes in europe. In RENT: Research in entrepreneurship and small business (pp. 1-15).

YEEP (2017) Empowering youth to heal the planet. Retrieved April, 2021 from https://www.meado wmaking.org/.

Zachariou, A., Kadis, K., \& Nicholaou, A. (2011). Sustainable development issues in education. Bank of Cyprus Cultural Centre.

Publisher's Note Springer Nature remains neutral with regard to jurisdictional claims in published maps and institutional affiliations.

\section{Authors and Affiliations}

\section{Antigoni Komodiki ${ }^{1}$ (D) Alexandros Charalambides ${ }^{1}\left[\right.$ [ $\cdot$ Andri loannou ${ }^{2}$ (i)}

Alexandros Charalambides

alexandros.charalambides@cut.ac.cy

Andri Ioannou

andri.i.ioannou@cut.ac.cy

1 Department of Chemical Engineering, Cyprus University of Technology, Limassol, Cyprus

2 Cyprus University of Technology, CYENS Center of Excellence, Limassol, Cyprus 